als durch die bis dahin üblichen Rundschreiben über Tagungen des djb, über die Arbeit, aber auch über das Leben des Verbandes zu unterrichten. Nicht zuletzt haben wir an solche Mitglieder gedacht, die eine Untergruppe - heute Regionalgruppe - nicht erreichen, um Informationen über den djb zu erhalten. „Monis Blättchen“ wurde geboren. Wissen Sie noch, was das ist? Kaum. Dr. Monika Lanz-Zumstein war damals für Öffentlichkeitsarbeit unseres Verbandes zuständig. Sie hatte es übernommen, eine regelmäßige Information - die ge-

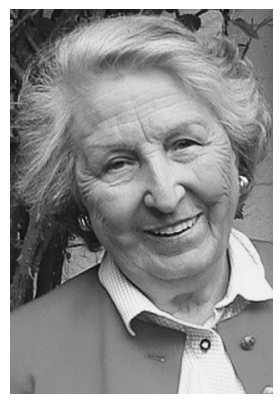

\section{Dr. Helga Stödter}

Schriftführerin im djb-Bundesvorstand (1967-1969), Mitglied des erweiterten djb-Bundesvorstands (1969-1975) seit 2005 Trägerin der Ehrennadel des djb für über 50-jährige Verbandsmitgliedschaft; Rechtsanwältin, Hamburg

Als ich Anfang der 50er Jahre - als Anwaltsassessorin - dem Juristinnenbund beitrat, ahnte ich nicht, welche Rolle er in meinem späteren Leben und bis zum heutigen Tage spielen würde. Erster Höhepunkt war 1950 meine Teilnahme am Juristentag in Frankfurt am Main, als Erna Scheffler ihre Thesen für ein neues Familienrecht erfolgreich vortrug. Nur beim Namensrecht protestierten die Kollegen!

Die folgenreichste Mitarbeit in einer Kommission war für mich jene zur „Reform des Unehelichenrechts“ unter dem Vorsitz von Maria Kramer-Schulz. Wir waren nur zu dritt. Anneliese Cuny war dabei. Ich war Berichterstatterin. Die meisten unserer Forderungen wurden später Gesetz.

Acht Jahre Vorstandsarbeit im djb waren kämpferische Jahre! Das ganze Familienrecht musste dem Grundgesetz angepasst werden - zum Teil gegen erbitterten Widerstand. Der djb fühlte sich vor allen anderen verantwortlich, für die Rechte der Frauen und Mütter einzutreten.

Der djb war Mitglied in der FIDA, dem internationalen Dachverband nationaler Juristinnenverbände. Das erste Mal nach dem Kriege sollte eine Deutsche Präsidentin werden. Weil nauen Zeitabstände erinnere ich nicht mehr - für alle Mitglieder unseres Verbandes zu erstellen. Mit viel Arbeit, wenig Geld und reichlich Charme hat sie dies auf den Weg gebracht. Zwei doppelt bedruckte Seiten, geheftet mit einer Klammer, waren es nach meiner Erinnerung am Anfang. Heute ist daraus unsere ebenso ansehnliche wie informative Verbandszeitschrift geworden.

Insgesamt waren es ausgefüllte und menschlich wie fachlich sehr bereichernde Jahre.

die Wunschkandidatinnen - Renate Lenz-Fuchs und Maria Kramer-Schulz - aus privaten und beruflichen Gründen ablehnten, wurde ich vom djb vorgeschlagen und 1973 in Penang/Malaysia zur Präsidentin gewählt. 1975 war dann der FIDA-Kongress in Hamburg, bei dem es um die „Rechte der Frauen in Familie, Beruf und Gesellschaft" ging. Viele Kolleginnen halfen bei den Vorbereitungen - mit Erfolg.

1972 wurde ich in die Ständige Deputation des Deutschen Juristentages gewählt. Unter anderem übernahm ich 1974 beim Juristentag in Hamburg den Vorsitz der Arbeitsrechtlichen Abteilung. Die meisten unserer Beschlussempfehlungen zur „Chancengleichheit der Frauen im Beruf“ wurden später zu Gesetzen. Wiederum aktuell: 1982 diskutierten Hertha Engelbrecht und ich bei der Schlussveranstaltung über ein Antidiskriminierungsgesetz (!), übrigens kontrovers. In den Jahren danach wurde die Förderung von Frauen für Führungspositionen (so auch der Name der Stiftung, die ich 1988 errichtete) zum Mittelpunkt meiner ehrenamtlichen Tätigkeit und ist es noch. Ich bin davon überzeugt, dass wir in Wirtschaft und Gesellschaft schon jetzt und noch mehr in Zukunft qualifizierte Frauen brauchen.

Wenn ich zurückblicke, dann sehe ich uns als Pionierinnen. Wir waren erfolgreich, weil wir gemeinsame Überzeugungen hatten und zusammenhielten. Aus Kolleginnen wurden Freundinnen. Es waren sinnvolle Jahre. Das wünsche ich auch der jüngeren Generation: gemeinsame Überzeugungen und die Entschlossenheit, sie solidarisch durchzusetzen und, auch dadurch, den Sinn unserer Aufgaben als Juristinnen zu erleben.

\title{
Neue Pressemitteilungen und Stellungnahmen
}

\author{
http://www.djb.de/stellungnahmen-und-pressemitteilungen/
}

\author{
Pressemitteilungen \\ o8-10 3. Bilanz Chancengleichheit - Stagnation auf nied- \\ rigem Niveau. Juni 2008. \\ 08-09 Netzwerk CEDAW-Alternativberichterstattung prä- \\ sentiert Forderungen in New York. Juni 2008. \\ 08-08 Netzwerk der Antidiskriminierungsorganisationen in \\ Deutschland wendet sich an EU-Kommissionspräsi- \\ dent José Manuel Barroso. Juni 2008.
}

\section{Stellungnahmen}

08-12 Zum Entwurf eines Gesetzes über genetische Untersuchungen bei Menschen (Gendiagnostikgesetz GenDG) vom 30. Juni 2008. 